\title{
If a Child Dies of Poverty, Hunger, Disease(s) and Pollution, Does Anyone Care?
}

\author{
J. T. Trevors
}

Published online: 13 October 2009

(C) Springer Science + Business Media B.V. 2009

Global pollution not only affects environmental health but also human health. About 11 million children die annually before the age of five. One billion children live under poverty conditions. Children cannot be born healthy (absence of disease) and remain healthy under poverty stricken conditions, lacking adequate food, potable water and in a contaminated environment (e.g., infectious diseases and chemical pollution). Poverty and pollution translates to hunger, illness, lack of health care and often death. Does anyone care? The answer is yes; some humans care, but still not enough is being accomplished to alleviate poverty and hunger, implement health care, reduce local, national and global pollution and provide universal birth control.

Humans living and working in polluted environments are subjected to a multitude of health risks including death. Contaminated water can contain a multitude of microbial diseases and vectors for diseases as well as metal and organic pollutants. Without infrastructure to prevent pollution and the resources to remediate the pollution, treat sewage and industrial wastes, the water supply is of no value for potable water. Yet in many locations, it is used for just that purpose. Water pollution generally does not exist in isolation from other forms of pollution.

Air pollution is a local, national and global environmental priority because of gas emissions and global

J. T. Trevors $(\bowtie)$

School of Environmental Sciences, University of Guelph, Guelph, ON, Canada N1G 2W1

e-mail: jtrevors@uoguelph.ca warming/climate change. Global warming will alter land usage, agricultural production, disease ranges, coastal areas, wetlands and water supplies. Global pollution like a disease pandemic and uncontrolled human population growth is a global problem. Global solutions are required now, and responsible science has an immense role in the solutions. At a time when global warming has started to impact on precipitation and agricultural production, there is a decline in agricultural teaching and research in many countries. The timing could not be worse! The earth is a big, hungry, overpopulated and warming planet that needs an immense amount of new agricultural research, technologies and education to provide sufficient food and reserves on local, national and global scales. Hungry humans need to be fed now.

We invite researchers to submit their best research to Water, Air and Soil Pollution so we can work as an international community of scholars to better humanity through science scholarship. Local descriptions of pollution in an area or country are generally not as valuable as new knowledge of the fate, transport and remediation of the pollution. Novel methods of pollution detection, solutions to pollution, new treatments, links between pollution and human/ environmental health and long-term successful laboratory- and field-tested studies of remediation processes and pollution are of immense value. The objective is to provide novel knowledge, solutions and new technologies to significant global pollution problems. The objective is responsible, novel science, not more of the same science. 